Vol. 12 (2) - Junio 2018 - http://dx.doi.org/10.21110/19882939.2018.1202

\title{
CONFUSIÓN DE LENGUAS ENTRE LOS PSICOANALISTAS
}

\section{Rafael Arroyo Guillamón ${ }^{1}$}

Tras el fallecimiento de Freud, el psicoanálisis ha tomado caminos muy diversos. En el mundo anglosajón, el predominio inicial de la corriente freudiana, representada por la Asociación Internacional de Psicoanálisis, ha dado paso hoy en día a nuevos y diferentes enfoques, entre los que destaca el paradigma relacional. El psicoanálisis francés, sin embargo, continúa liderado por las propuestas de Jacques Lacan y su particular lectura de la obra del maestro vienés. No obstante, en cada uno de estos ámbitos no han dejado de ocurrir escisiones, dando lugar a multitud de agrupaciones y escuelas. Cada institución tiene sus autores favoritos, conceptos fetiche y prácticas propias, y no suele existir un verdadero intercambio entre las distintas corrientes que, sin embargo, se reconocen todas herederas del legado freudiano. Este artículo pretende reflexionar sobre las consecuencias de este aislamiento y propone afrontar las diferencias con curiosidad y respeto, para establecer entre las diversas instituciones un diálogo colaborativo y plural que fortalezca la disciplina psicoanalítica.

Palabras clave: Freud, psicoanálisis relacional, Lacan, instituciones psicoanalíticas, diferencias, diálogo.

Following the death of Freud, psychoanalysis has taken many different routes, translating into a flourishing of diverse schools and traditions. In the Anglo-Saxon world, the initial predominance of the Freudian current, represented by the work of the International Psychoanalytic Association, has now given way to new and different approaches, amongst which the relational paradigm stands out. French psychoanalytic thought, however, continues to be heavily determined by the work of Jacques Lacan and his particular reading of Freud's own work. Notwithstanding, within each of these contexts, there have been many further scissions and splits, giving rise to a variety of schools and approaches. Each institution has its favorite authors, fetish concepts and own practices, and there is usually no real exchange between the different currents that, nevertheless, are all recognized as the inheritors of the Freudian legacy. This paper aims at reflecting over the consequences of such longstanding inter-school isolation and proposes ways of facing the differences respectfully, with openness and curiosity. It assumes that only by way of collaborative and pluralistic dialogue between the different psychoanalytic thoughts and institutions, the psychoanalytic discipline as a whole will be strengthened.

Key Words: Freud, relational psychoanalysis, Lacan, psychoanalytic institutions, differences, dialogue.

\section{English Title: CONFUSION OF TONGUES AMONG PSYCHOANALISTS}

\section{Cita bibliográfica / Reference citation:}

Arroyo Guillamón, R. (2018). Confusión de lenguas entre los psicoanalistas. Clínica e Investigación Relacional, 12 (2): 318-335. [ISSN 1988-2939] [Recuperado de www.ceir.info ] DOI:

10.21110/19882939.2018.120206

\footnotetext{
${ }^{1}$ Psiquiatra y psicoterapeuta psicoanalítico. Servicio de Psiquiatría del Hospital Universitario Infanta Sofía, San Sebastián de los Reyes (Madrid). Centro Psicoanalítico de Madrid. Contacto: arroyoguillamon@gmail.com
} 
Vivir siempre la vida de otra persona, ¿tiene algún valor? ¿Una vida así no es ya casi la muerte? ¿Pierdo demasiado si arriesgo esta vida? ¿Chi lo sa? S. Ferenczi (1932)

\section{Geografía del campo psicoanalítico}

Desde sus orígenes, en la Centroeuropa de finales del siglo XIX, el legado psicoanalítico se ha diseminado enormemente por el campo, cada vez más inabarcable, de las psicoterapias. Una dispersión que encuentra su razón de ser en la diversidad de planteamientos sobre el psiquismo humano -incluidos los de disciplinas ajenas al campo psi- que se han agregado al descubrimiento-construcción freudiano del inconsciente. Además, como suele ocurrir con las ideas originales, el mismo empuje que sirvió para alumbrarlas puede convertirse en cierto empeño en que se mantengan intactas a lo largo de los años, generando en ocasiones el efecto contrario al pretendido. Quizás, algo de esto alcanzase al propio Freud, que viendo peligrar la pureza de sus propuestas y preocupado por las primeras disidencias, creó el Comité secreto de los siete anillos. Lo cual no impidió que poco tiempo después, en esa élite de príncipes herederos, aparecieran fuertes divergencias que acabarían en rupturas irreconciliables con el maestro (Ferschtut, 2002).

Ya al final de sus días, viviendo en Londres, Freud — que dos décadas antes había fundado la Asociación Internacional de Psicoanálisis (IPA) - delegó en su hija Anna la continuidad de su obra. Sus trabajos, intentando sistematizar las ideas de su padre y aplicándolas a la práctica con niños, contribuyeron al vigoroso crecimiento que experimentó el psicoanálisis en los años cincuenta y sesenta. Especialmente en Norteamérica, a donde el exilio de analistas europeos —véanse Hartmann, Kris, Loewenstein o Rapaport- y la aparición de figuras autóctonas - como Greenson-consolidaron el anafreudismo, que bajo el nombre de psicología del yo ocupaba los institutos de formación y los consultorios privados de la gran potencia (Delahanty, 1992).

Para cuando ocurriera el traspaso de poder, Melanie Klein ya ejercía una gran influencia en la Sociedad Británica de Psicoanálisis. Extendiendo las elaboraciones freudianas sobre la pulsión de muerte y muy influenciada por sus analistas -Ferenczi y Abraham-, Klein planteó novedosas ideas sobre los objetos y fantasías que constituyen el mundo interno infantil, que derivaron en una práctica con niños muy alejada de la orientación pedagógica de Anna Freud. En las siguientes décadas, una legión de discípulos 
—Rivière, Isaacs, Heinmann, Bion, Rosenfeld, Meltzer etc.— aplicó sus conceptos al trabajo con pacientes psicóticos y a las terapias de grupo; sobre todo en Latinoamérica, donde hacia los años setenta el psicoanálisis había tomado claramente el sendero kleiniano (Segal, 1985).

Quienes no desearon formar parte de la batalla entre las dos grandes damas conformaron el llamado grupo independiente -Winnicott, Fairbairn o Balint, entre otros-, que recogiendo influencias de ambas constituyó, con el paso de los años, la corriente británica de mayor influencia. Este espíritu integrador y alejado de posiciones rígidas tuvo sus resonancias americanas en la extendida psicología del self, fundada por Kohut, o en autores como Pichón Rivière, Bleger o los Baranger en el mundo hispanohablante (Velasco, 2009; Aguirre, 2015).

Con el tiempo, en Norteamérica a muchos analistas les resultaba difícil adscribirse sólo a la psicología del yo — centrada en el conflicto edípico y el modelo estructural—, ni conjugaban del todo con los aportes socioculturales de la teoría interpersonal de Sullivan y de los humanistas como Karen Horney o Erich Fromm. De modo que cada vez más colegas de orientaciones diversas aunaban más similitudes que diferencias en torno a un modelo que primaba el encuentro entre las subjetividades de paciente y analista. Así, a las primeras teorías intersubjetivas, lideradas por Stolorow, Atwood y Orange —cercanos al enfoque kohutiano-, se añadieron las influencias del posmodernismo, el construccionismo social y el feminismo. Stephen Mitchell y sus discípulos (Levenson, Bromberg, Benjamin, etc.) popularizaron para esta aglutinación de corrientes el nombre de enfoque o paradigma relacional (Aron, 2013). Ya fuera de esas fronteras, el así llamado psicoanálisis relacional se ha consolidado en muchos territorios como una interesante alternativa a las tradicionales ideas de la IPA. Dan buena cuenta de ello, en nuestro medio, representantes como Ávila Espada y Rodríguez Sutil en Madrid o Coderch y Tizón en Barcelona, entre otros.

\section{La revolución francesa}

Nada muy diferente a esta dispersión angloamericana ocurrió en el psicoanálisis francés, que a comienzos de los años cincuenta estaba liderado por la Sociedad Psicoanalítica de París, perteneciente a la IPA. Discrepancias técnicas respecto a la duración de las sesiones y a la práctica del análisis por los no médicos, llevaron a una fuerte división en su seno entre los seguidores de su autoritario presidente, Sacha Nacht, y un sector crítico encabezado por Daniel Lagache, al que pronto se unió su vicepresidente, Jacques Lacan. Las diferencias se saldaron con la creación de la Sociedad Francesa de Psicoanálisis (SFP), que se constituyó aspirando a pertenecer también a la IPA, si bien esto nunca ocurrió y la SFP no pasó de ser considerada por aquella como un grupo de estudio (Malecki, Matanó y Zuzulich, 
2013). Cansado de esta situación, en 1964 Lacan funda la Escuela Freudiana de París (EFP), buscando lo que denominó "la reconquista del campo freudiano" y en medio de una fuerte polémica entre aquellos de sus seguidores que no querían renunciar por completo al vínculo con el psicoanálisis tradicional (Lacan, 2012). Durante sus dieciséis años de existencia, la EFP fue el núcleo de uno de los períodos más importantes en la obra de Lacan y aglutinó a su alrededor a importantes figuras del panorama cultural europeo. No obstante, en 1980, harto de las dificultades institucionales, Lacan termina por disolver su propia escuela concediendo a su yerno, el filósofo Jacques-Alain Miller, la coautoría de sus famosos seminarios y confiándole la tarea editar los que aún no estaban publicados (Gómez, 1980; Bellver, 2014). De forma similar a lo ocurrido con el círculo íntimo de Freud, Miller se convirtió en el principal garante de la transmisión de la enseñanza de Lacan y, junto a muchos de sus discípulos en todo el mundo, fundó en 1992 la Asociación Mundial de Psicoanálisis (AMP), cuyo instituto de formación continúa dirigiendo a día de hoy.

Pero como ya ocurriera con la IPA para el mundo freudiano, las diferencias respecto a la corriente oficial, liderada por Miller, provocaron en los años sucesivos que algunos lacanianos se escindieran de la AMP, fundando redes paralelas como la Escuela de Psicoanálisis de los Foros del Campo Lacaniano, de la que forma parte una destacada analizante de Lacan, Colette Soler. Otras asociaciones, desde un inicio ajenas a la AMP y en su mayoría latinoamericanas, se agruparon en el movimiento Convergencia que incluye, entre otras, a la Escuela Freudiana de Buenos Aires, a la que han pertenecido importantes pensadores del mundo lacaniano como Oscar Massotta, introductor de la obra de Lacan en España, Isidoro Vegh o Ricardo Rodríguez Ponte, traductor de conocidas versiones críticas de su enseñanza.

A uno y otro lado del Atlántico, entonces, el tronco psicoanalítico freudiano ha crecido desde sus inicios dividiéndose en multitud de ramas que conforman hoy un complejo entramado de corrientes y escuelas, cada cual con sus diferentes maestros, conceptos fetiche y términos propios. Tales ramificaciones representan para algunos el peligro de desaparición del psicoanálisis, en tanto pueden disolverse en ellas los mínimos comunes que garanticen su especificidad. No obstante, para otros son el mejor ejemplo del continuo crecimiento y transformación que, lejos de debilitarla, refuerza en cada escisión la vitalidad de esta disciplina.

\section{Las estaciones recorridas}

Actualmente no basta con que un colega se presente como analista sin que, al menos, concrete bajo qué institución, junto a cuáles autores y con qué idea del inconsciente 
se reconoce como tal. Lo que da una pista de por dónde inició el largo viaje de su formación y las estaciones en que se detuvo hasta llegar al destino desde el que hoy ejerce su práctica.

Siendo que desde el comienzo mi labor como psiquiatra ha estado ligada a la asistencia pública, a las personas con dificultades graves de salud mental y, muy especialmente, a la psicoterapia de grupo, los primeros años de mi formación han ido de la mano de conceptos derivados del kleinismo y la teoría de las relaciones objetales. Es por ello que nunca ha dejado de resultarme útil su lógica — que ahora ya no juzgo como la únicabasada en la física y la geometría clásicas, y su concepción tradicional del tiempo, el espacio, la materia y la energía. Resonaban, por lo tanto, en los conceptos que me enseñaron identificación, introyección, proyección, contratransferencia, etc.- las ideas del Freud más biólogo que establecían un aparato psíquico asimilado al cerebro de la medicina, es decir, asentado en el interior de un cuerpo con una clara materialidad. Una mente, digamos, corporeizada que, al modo de una esfera, tendría bien diferenciado su interior, repleto de cargas energéticas, de un exterior con el que, a lo largo del tiempo —un tiempo siempre cronológico y lineal-, pudieran transferirse dichas cantidades de adentro a fuera y viceversa. Así, según Klein y sus discípulos, el mundo interno se conformaría en base a estos intercambios entre aspectos parciales de los individuos, identificados con ciertos recortes del cuerpo (el pecho, el ano, el pene, la vagina, etc...) que la tradición psicoanalítica ha situado como zonas privilegiadas de asiento de la pulsión; y que, materializados como objetos, se califican — con cierto tinte moralista-como "buenos" y "malos", o las fuerzas que los animan, en cuanto a su fin, como "de vida" $y$ "de muerte".

Sin embargo, en los últimos años me siento cada vez más atraído por la singular lectura de Freud que realizó Jacques Lacan y las sorprendentes propuestas con que, a partir de ella, subvirtió el mundo psicoanalítico. Este interés se ha traducido en un creciente acercamiento a su enseñanza que, si bien sinuoso y plagado de obstáculos, resulta enormemente estimulante por cuanto interpela en lo más íntimo de su ser a todo aquel que se acerque a sus textos con ánimo de trabajarlos. A saber, su ignorancia, la radical ausencia de palabras para representar esa dimensión siniestra, azarosa e imposible de nombrar, que no obstante $-y$ en ello creemos en tanto psicoanalistas- gobierna nuestras vidas.

Ahora bien, cierto espíritu crítico e inconformista me está llevando por este camino olisqueando aquí y allá, tras los pasos de diversos comentadores, escuelas e instituciones sobre Lacan que, reconociéndose todos ellos como fieles seguidores, divergen notablemente en sus planteamientos. Y, para mayor complejidad, resistiéndome a abandonar del todo lo aprendido de autores marginales al psicoanálisis francés, convencido de que su forclusión - por emplear un término emblema de esta orientación— puede expresa. Este material es para uso científico y profesional exclusivamente y puede contener información clínica sensible. Los editores no se responsabilizan de los contenidos de los autores. Dirigir las consultas sobre derechos y autorizaciones a ceir@psicoterapiarelacional.es 
convertir nuestra disciplina en una práctica religiosa, siendo este riesgo, en mi opinión, más peligroso que el de caer en una confusa babelia de conceptos, como suelen denunciar quienes se cierran a tal apertura. Esta actitud me ha procurado situaciones ciertamente cómicas como en la que, de camino en tren a mis primeras jornadas organizadas por una institución lacaniana, leía un texto que no podía estar más alejado, en su lenguaje y sus planteamientos, de las ideas que me aguardaban en mi destino. Caí en la cuenta de que aquella escena podía pensarse como una cierta escisión de mi yo-analista, al leer las siguientes líneas referidas al encuadre en el análisis de niños:

La firmeza en el manejo del problema de la separación en la sala de espera de un niño pequeño puede brindar material en relación con la identificación proyectiva con el perseguidor, lo cual requiere poner límites a la conducta agresiva. Esto puede conducir a material edípico femenino pasivo lo cual requiere (...) restricción sobre el contacto corporal: esta restricción puede provocar angustia de castración masculina y el impulso homosexual a reducir y aplacar con caramelos de bolsillo, lo cual llevará a (...) las razones que tiene el analista para rechazar este $u$ otros regalos. Una explicación puede llevar a una conducta expulsiva anal de índole maníaca y la necesidad de defecar, lo cual requiere (...) la insistencia del analista en acompañar al niño al baño y la elaboración de detalles en torno de la ayuda real que el niño necesita para desvestirse, vestirse, limpiarse, apretar el descargador, etc., a diferencia de su seducción por un lado y de su ansiedad persecutoria por otro y así sucesivamente (Meltzer, 1996, p.40).

\section{El despertar de la angustia}

La terminología del texto rápidamente sitúa a su autor en la línea del pensamiento kleiniano. Donald Meltzer representó en sus inicios unos de los más fieles acólitos de Melanie Klein. Con el paso de los años y bajo la influencia de otro gran discípulo de la psicoanalista vienesa, Wilfred Bion, de quien siempre se confesó admirador, Meltzer se distanció de su maestra y llevó a cabo sus propias elaboraciones, por las que se le reconoce hoy como un destacado autor post o neo kleiniano (Saraspe, 2016).

El proceso psicoanalítico - así se titula el libro que me hallaba estudiando-realiza un detallado recorrido por las distintas fases que atraviesa el análisis de niños y plantea numerosas cuestiones de orden práctico. En especial, respecto a las ansiedades que se apoderan del infante en la relación transferencial y su modulación por parte del analista mediante el manejo del encuadre y su actividad interpretativa durante el proceso. 
Fue en virtud del paralelismo con el paciente grave, en el que habitualmente aprecio regresiones infantiles y la necesidad de un terapeuta que ejerza como continente emocional, que el libro de Meltzer me estaba resultando de gran interés. Sin embargo, me dirigía a un ambiente que se postula muy crítico con la identificación proyectiva y la contratransferencia, por considerarlas fenómenos de orden imaginario que, lejos de ayudar, interfieren al analista en su función (Lacan, 2013a, 2013b).

El título de las jornadas de aquel fin de semana, El despertar de la angustia, reflejaba bien lo que podría ocurrir a quien se acerque a estos encuentros — como era mi caso- con cierta ingenuidad y una actitud abierta al intercambio entre las distintas escuelas. Me llamó la atención, a mi llegada, la escasez de público para un encuentro de carácter nacional, así como la media de edad del auditorio que pronto me situaba entre los escasos "jóvenes" presentes; lo que me hizo pensar en la falta de recambio generacional que encontramos, cada vez con menos sorpresa, en bastantes instituciones psicoanalíticas.

Respecto a las ponencias, realizaron entre todas ellas un amplio recorrido por el tema que nos convocaba: la angustia. Para destacarla, como ya hiciera Freud, como respuesta a las primeras vivencias de desamparo, aún siendo bebés, que inscritas como huellas en nuestro psiquismo constituirán más adelante una señal de alerta ante posibles peligros. Como se explicitó, ya en los términos en que fue estudiada por Lacan, la angustia constituye un afecto que no engaña, el síntoma tipo del advenimiento de lo que, en esta orientación, se considera lo más real para el sujeto, es decir, aquello que da cuenta del desencuentro, de la desproporción, de la ausencia última de entendimiento entre los seres hablantes, que el maestro francés había descrito con el aforismo "no hay relación sexual". Se destacó, además, la función de la angustia como soporte del fantasma, esa ficción inconsciente construida por palabras e imágenes con que cada sujeto intenta — sin conseguirlo nunca del todo- encontrar un sentido a su imposibilidad, consecuencia del lenguaje en que se ve envuelto. También se discutió, apoyándose en las formulaciones matemáticas de la última enseñanza de Lacan, sobre las distintas soluciones o anudamientos con que cada sujeto trata de mantenerse relativamente estabilizado. Finalmente, se abordó a la angustia como una experiencia de destitución subjetiva facilitada por contexto sociopolítico actual, que nos convierte en meros objetos del sistema capitalista. $Y$ se describieron detalladamente sus formas de presentación a través del relato de distintas escenas de una bella novela.

Sin ninguna duda, mi escaso recorrido en esta orientación condicionaba enormemente la escucha, que se me hacía muy difícil en algunos instantes. No obstante, esto me llevó a pensar si algo de aquello que estaba experimentando pudiera tener relación con los sectarismos que tocan al psicoanálisis. Me pareció, por momentos, que se utilizaba un expresa. Este material es para uso científico y profesional exclusivamente y puede contener información clínica sensible. Los editores no se responsabilizan de los contenidos de los autores. Dirigir las consultas sobre derechos y autorizaciones a ceir@psicoterapiarelacional.es 
lenguaje muy enrevesado y distinto al del discurso psicoanalítico usual. Cargado de aforismos que se repetían casi calcados por varios de los ponentes, todos ellos citas textuales del propio Lacan o referencias a autores franceses continuadores de su pensamiento. En cualquier caso, se dio una ausencia completa de alusiones — salvando al propio Freud-a trabajos sobre la angustia por fuera del campo lacaniano. Asimismo, me resultó complicado, en varias de las ponencias, establecer un hilo conductor del contenido con mi trabajo como clínico, de modo que los argumentos de la mayoría de las exposiciones me parecían sostenidos en disquisiciones epistémicas. No obstante, la cuidada organización del evento había previsto en cada una de las mesas una ponencia referida a un caso clínico. Pero, para mi sorpresa, en el intercambio posterior y en los comentarios entre el público, estas viñetas clínicas gozaron de las mayores críticas. En general, me extrañó tono severo y en ocasiones fiscalizador del auditorio para con los ponentes, que por otra parte eran compañeros de formación e ideología bajo la misma institución. Así, parecía que las especulaciones teóricas, por muy disonantes que resultaran, gozaban de cierto respeto a su enunciante, pero al aplicarlas al caso concreto afloraban las diferencias y la necesidad de cada uno, legitimando su criterio como mejor que el del colega, de ser reconocido como más psicoanalista o más lacaniano.

\section{La trastienda del psicoanálisis}

Como suele ocurrir en estos encuentros, es por fuera de la escena oficial de los conferenciantes y el público —en los descansos, en las charlas de pasillo y al relajo de las comidas y cenas- que uno puede conocer más de cerca los entresijos de las instituciones.

Siendo que apenas conocía a los asistentes, pude intercambiar impresiones con varios de ellos, que con gran amabilidad hicieron de anfitriones en mi visita. Fue entonces que algunos me confesaron que su dilatada formación había transitado siempre por el eje Freud-Lacan, desconociendo la lectura de otros autores o corrientes dentro del psicoanálisis. Pude también preguntarles sobre la gran importancia que conceden al análisis del futuro practicante. No en vano, lo consideran el elemento clave en la formación del analista, de modo que el reconocimiento "oficial" como tal ocurre cuando el candidato da cuenta de las vicisitudes de su análisis a la institución, en el llamado procedimiento del pase. Mi opinión coincide con este papel primordial de la experiencia del inconsciente para el desarrollo de la función analítica. Aunque quizá no hasta el punto de algunos colegas, que argumentaban convencidos que si este análisis no es llevado por un analista lacaniano —tal es mi caso- difícilmente podrían comprenderse en profundidad los textos y enseñanzas de Lacan. expresa. Este material es para uso científico y profesional exclusivamente y puede contener información clínica sensible. Los editores no se responsabilizan de los contenidos de los autores. Dirigir las consultas sobre derechos y autorizaciones a ceir@psicoterapiarelacional.es 
Otra cuestión que me pareció curiosa, por cuanto he podido observarla en varias escuelas, es que, dado que la institución organizadora hacía años se había escindido de la corriente oficial, alguno de mis anfitriones denunciaba a ésta por su funcionamiento conservador e inmovilista. Y juzgaba en ella, a pesar de su aparente horizontalidad, una organización de tipo eclesiástico donde la transmisión de la enseñanza de Lacan estaba muy condicionada por la opinión del líder, poco dado al diálogo con otras interpretaciones de sus textos. En este sentido, me hablaban de mayores bondades en la presente escuela, cuya ordenación estaba diseñada para que nadie ocupase el lugar de un gurú, con una rotación prefijada y obligatoria de los cargos y mucho más tolerante al intercambio entre colegas, aun con diferentes concepciones.

Varias de las personas con quienes disfruté de interesantes charlas se sorprendían de mi condición de psiquiatra, ya que, como vengo observando en los círculos analíticos $-\mathrm{y}$ especialmente de esta orientación-, escasean los médicos, lo que no deja de ser paradójico dada la formación del propio Lacan. El psiquiatra francés defendió enérgicamente -más aún que el propio Freud, que ya se había pronunciado a favor del análisis ejercido por los legos-que otras profesiones accedieran al psicoanálisis, así como juzgaba imprescindible incluir en la formación de todo analista materias como la filosofía, la lingüística y las matemáticas. De forma que entre mis colegas se encontraban, además de una mayoría de psicólogos, filósofos, maestros, sociólogos, etc.

Entre los más jóvenes eran pocos quienes podían vivir de su práctica como psicoanalistas. Ni siquiera como clínicos, debiendo compaginar muchos de ellos la atención a pacientes -en su mayoría a nivel privado- con puestos administrativos, en la enseñanza o en otros terrenos más o menos ajenos a la salud mental. Pude, no obstante, departir también con compañeros veteranos. Algunos verdaderos referentes en la institución, de quienes la fama que le había procurado su experiencia clínica o su trabajo teórico despertaba tanta admiración en algunos como recelo y envidia entre otros. Me pareció que les hacía cierta gracia las preguntas de alguien cuyas características lo convertían en una rara avis en aquel foro: joven, médico, trabajando a nivel público y, a pesar de ello, jinteresado en Lacan! Mi curiosidad fue respondida con preguntas acerca de mi formación, que rápidamente acabaron en miradas de complicidad entre ellos al oír que la institución a la que pertenezco es plural y da cabida a varias orientaciones. "O sea... un mix, ¿no?" me espetaba una compañera, dejándome entrever cierta desaprobación en sus palabras.

Finalmente, la gentil acogida recibida me dio la oportunidad de conocer, en momentos más distendidos, algunas de las desavenencias y rupturas que, como en cualquier otra institución, habían provocado escisiones. No sólo a nivel nacional, donde las escuelas 
regionales se agrupaban en distintas federaciones, sino en territorios locales donde en poblaciones relativamente pequeñas, con escaso número de analistas, éstos habían terminado por constituir subgrupos de funcionamiento paralelo.

\section{EI DVD del analista}

Comoquiera que cuando acudo a un encuentro formativo termino por entusiasmarme un buen tiempo con lo aprendido allí, en el viaje de regreso me consagré a la lectura de un libro que adquirí de uno de los stands de las jornadas: Lacan el borromeo. Ahondar en el nudo, de Michel Bousseyroux (2016). Entre sus primeras páginas, figura un capítulo de título atrayente, El DVD del analista, dedicado a aclarar qué es lo que define a un analista en función de tres características — de las que extrae las mencionadas siglas- que sostienen su posición ética. A saber, su deber, su voluntad y su deseo.

En cuanto al deber, Bousseyroux se refiere a la famosa máxima freudiana en relación al fin de análisis: Wo Es war soll Ich werden, traducida por Lacan como "allí donde ello era, lo que es Yo debe advenir". El autor matiza el significado en alemán de los dos verbos de la oración: soll (debe) no se refiere tanto a una obligación que no deja elección, sino a una invitación a hacer, un consejo o recomendación que se puede ignorar. Respecto a werden (advenir, empezar a hacer) se pregunta ¿qué es aquello que debe empezar a hacerse en la experiencia analítica? Concluye que el aforismo de Freud resulta un imperativo utópico, pues no es frecuente que el yo logre ese deber de advenir en el lugar del goce del síntoma. Más bien, ese fenómeno es del orden de lo posible, de lo que puede no ocurrir. Bousseyroux cita la advertencia de Lacan en su Seminario sobre La ética del psicoanálisis: que el analista haya "tomado la medida de que hay algo que no puede no evitar, y que eso es lo real" (p.39). El encuentro con lo real, por tanto, definido en términos freudianos como un yo capaz de representar en su totalidad al ello, es decir, la posibilidad de cernir por completo con palabras el goce pulsional, resulta entonces imposible. Es por ello que la ética del analista encontrará su fundamento no en la lógica de ese ideal, sino en la particularidad, en que exista alguien cuyo yo ya no tiene que advenir porque se ha hecho con la dimensión de su falta, de su imposibilidad para dar sentido a todas sus experiencias. El deber del analista, entonces, es el deber de interpretar. Pero lejos de descifrar o construir significados o resumir, la interpretación debe leer en lo que la palabra del analizante no dice: la demanda pulsional, pues "ella es la locomotora de la palabra, que tira, en su repetición, de los vagones de los significantes del tren llamado Deseo" (p.51). Demanda gozada a la que se accede operando, precisamente, mediante los cortes y las caídas del sentido. Así, "a un analista no lo hace que 
haya sido "suficientemente" analizado, que haya descifrado suficientemente su inconsciente y su síntoma. Lo que hace al analista es (...) su disposición a lo real" (p.59).

De este modo, si la voluntad es, al decir de Spinoza, un esfuerzo para perseverar en el ser, Bousseyroux señala que el analista "no tiene que perseverar en el ser sino, en el deser" (p.56). Su voluntad no puede estar basada en el goce de una escucha que apunte al saber, sino que debe mantenerse donde se aloja la angustia, en la destitución del sujeto que corresponde al vaciamiento del sentido, con la caída del supuesto saber de la transferencia.

Por último, el deseo del analista debe alejarse de toda dependencia. A ella le llevaría reducirse exclusivamente a la demanda del analizante. Más que en una ética del deseo, estaría sostenido en una moral de la culpabilidad, regida por el ideal del bien fundado por Aristóteles. El analista debe franquear ese más allá del placer cuyo principio había formulado Freud. Afirma el autor: "la ética del análisis no es una especulación que lleva a servir a los bienes propios de la moral del poder, sino que se inscribe en la experiencia trágica de la vida" (p.42).

Vemos, pues, que el deber, la voluntad y el deseo conforman, según Bousseyroux, ese DVD del analista que debemos leer con el lector de la ética de Lacan, alejándonos de la exigencia ideal que enarbola la propuesta freudiana. Ésta promete al analizante, desde la atalaya del saber, encontrar hasta el último sentido de su vida, estimulando un deseo que, de forma falaz, se le presenta como finito y susceptible de colmarse.

\section{Del fracaso institucional}

Dediqué los días que sucedieron a aquellas jornadas a reflexionar sobre los citados atributos que hacen a un analista. En concreto, sobre si dicha función queda restringida al dispositivo analítico o se es analista, también, en los contextos de enseñanza y formación como del que acababa de regresar. En tal caso, podríamos pensar con la misma lógica algunas de las escenas que viví en aquellas jornadas, por lo demás similares a las de cualquier otra institución psicoanalítica. Así pues, la transmisión del conocimiento que allí se proponía resultaba, en mi opinión, no muy cercana a la ética sugerida por Lacan. En tanto dejaba entrever un camino abonado por el deber obligatorio, más que centrado en la posibilidad (de seguir sólo a ciertos autores, de realizar determinado tipo de análisis, etc.); en una voluntad entregada al "padre-severo" (tomando la homofonía con que Lacan equipara "persevero" con "père-severe"); y a un deseo que responde más al prototipo de psicoanálisis de ese colectivo que al modo singular en que cada uno deviene analista. 
En su artículo El fracaso de las instituciones "psicoanalíticas", Michel Sauval (1998) se ocupa ampliamente de todos estos fenómenos que hacen zozobrar las naves de la herencia freudiana. Critica las deudas o reconocimientos que cada escuela se ve obligada a tributar a determinadas figuras, lo que, según afirma, "nos mantiene, respecto del problema, al nivel de una relación con el padre" (p.6) y no lleva sino a la constitución de una ortodoxia que, sometiendo el psicoanálisis al discurso del amo, precipita a sus organizaciones hacia aquello que denuncian en las escuelas vecinas.

Sauval cita a René Mayor:

El poder que se desarrolla en el seno de las instituciones reposa demasiado a menudo sobre la falta de resolución de las transferencias, sobre el sometimiento a una ideología dominante y a su código lenguajero, que sirven más para preservar los controles sociales y burocráticos que para abrir nuevas fronteras a la investigación y la extensión de nuestros conocimientos (p.10).

Existe para el autor, a nivel internacional, un sistemático, histórico y repetido fracaso de todas las experiencias que han pretendido construir instituciones específicamente psicoanalíticas, valga decir, fundadas sobre lo más propio de su teoría y su práctica. Lo cual lleva una y otra vez al problema de la selección de los analistas y a la garantía que la institución les concede sobre su práctica. El análisis didáctico y la práctica estándar han sido históricamente el fundamento de la garantía que otorga la IPA, así como el procedimiento del pase, en la AMP, verifica los efectos que darían cuenta de que en determinado candidato hubo acto analítico.

El artículo analiza también el error que supone olvidar la alienación al modo de producción capitalista y al régimen de las mercancías, no haciendo un lugar necesario a las leyes de la economía, ya que "la práctica analítica no deja de ser también una mercadería" (p.22). No puede dejar de reconocerse en todo el conjunto de servicios y prestaciones que conforman el circuito psicoanalítico: supervisiones, enseñanza, derivaciones, etc.

El analista debe querer el dinero de sus pacientes (querer cualquier otra cosa sólo puede conducir a lo peor, en particular, querer el "bien" del paciente). Pero el analista también debe poder resignar el dinero. Aunque más no sea, porque es la condición para que un final sea posible (p.37).

Por lo demás, se analizan también las desviaciones en que frecuentemente incurre el psicoanálisis actual. Desde las diferentes interpretaciones posibles de los textos especialmente de Lacan-, pasando por la franca desvalorización que supone la duración cada vez mayor de los análisis en una cultura marcada por la rapidez, hasta, finalmente, expresa. Este material es para uso científico y profesional exclusivamente y puede contener información clínica sensible. Los editores no se responsabilizan de los contenidos de los autores. Dirigir las consultas sobre derechos y autorizaciones a ceir@psicoterapiarelacional.es 
pensar al psicoanálisis como respuesta a todos los males de la sociedad. A este respecto, Sauval se muestra crítico con la extensión del psicoanálisis fuera del campo de la neurosis:

El propio Lacan no dejaba de subrayar (...) que era la extensión sobre otros campos (niños, psicosis, etc.) la que había generado (...) una serie de malentendidos y confusiones sobre lo propio de la práctica analítica. El dispositivo analítico es indisociable de la histeria (...). El día que la neurosis no responda más a la subjetividad de la época, el psicoanálisis habrá desaparecido como hecho histórico. (...) Surgirán quizás otras prácticas. Pero no será psicoanálisis. (...) no deben ser campos a los que el psicoanálisis deba renunciar. Pero sin perder de vista cual es nuestro campo de partida... y de retorno (p.40).

Por último, el autor realiza una serie de proposiciones para mejorar la institución psicoanalítica, entre las que incluye tener presente a los no analistas, tanto para su participación directa como para la discusión de problemas en los que el psicoanálisis encuentra sus límites. Asimismo, plantea que el eje de una institución no pueden ser los criterios de selección, es decir, de exclusión. Aboga por un funcionamiento democrático, basado en asambleas abiertas, en el que predomine la escucha, la tolerancia, el debate, la amplitud y se facilite "la discusión con los psicoanalistas de todas las extracciones institucionales y de todas las orientaciones" (p.42).

\section{Discusión: ¿una lengua que no nos confunda?}

Mucho se ha escrito ya sobre las vicisitudes de las instituciones psicoanalíticas. Si comparamos su funcionamiento con el de un grupo, veremos que están siempre sujetas a movimientos relativos a su discriminación. Sea por un déficit de ésta, que lleva a la identificación en masa con lo semejante, tratando de evitar la diferencia con el otro y, en definitiva, la falta de su reconocimiento. Esta ausencia de investimiento externo sacude la identidad del grupo y le abandona a angustias muy intensas que amenazan con su disolución. O bien, en el otro extremo, el grupo puede verse concernido por un exceso discriminador, separatista, por la incapacidad para reconocer aspectos propios que, no pudiendo tolerar, sólo se identifican en un otro que se desea alejado y se convierte en el basurero inconsciente de sus deshechos psíquicos. Ambos escenarios no son sino diferentes caras de una misma moneda, de la que dependerá el valor, en la economía psíquica de todo grupo -en realidad de cualquier mente en desarrollo- de lo imaginario, de lo especular y, por tanto, del narcisismo. Pues es en lo referente a la imagen y a su carácter engañoso (ya que está ligada a la fantasmática de cada cual) y a su condición de espejo (es decir, a la distinción de lo propio y lo ajeno) que ese desequilibrio de fuerzas contrapuestas, entre alienarse o separarse, instituye nuestro psiquismo. La mente se conforma en tanto que estos 
procesos de identificación y diferenciación dan lugar a: la representación imaginaria de un cuerpo unificado y completo, al sentimiento de sí que conlleva, que funda nuestro yo, y, a partir de él, a la creencia en dos realidades, interna y externa, diferenciadas. Todo esto acontece bien lo enfoquemos desde la novela edípica y las fantasías intrapsíquicas que la acompañan, bien desde la trama relacional formada por la interacción entre sus personajes, o por el carácter significante que comporta su discurso.

Si la dimensión narcisista resulta entonces determinante en la constitución del aparato psíquico, las circunstancias que la compliquen darán lugar a estancamientos importantes de la capacidad de representar o simbolizar, al modo de las personas con dificultades graves de salud mental. Es por ello, seguramente, que García Badaracco (2010) se refirió a las guerras de narcisismos en las sociedades psicoanalíticas como efecto de la mente cerrada, funcionamiento que domina el psiquismo del paciente grave. Así, en muchas de estas instituciones se sostiene la identidad psicoanalítica en base a defensas muy enérgicas, proporcionales a la angustia que despierta la amenaza de no reconocimiento que arrastra el psicoanálisis desde sus comienzos. Por un lado, la pertenencia a estos colectivos se apuntala en unos criterios estándar que, elevados a la condición de ideal, suponen una pesada exigencia para quien quiera convertirse en analista, además de dejar a un lado la singularidad del candidato. Por otro, se rechazan — con más o menos empeño—otras posibilidades por fuera de ese estándar, que cada institución coloca en determinados elementos: el estudio de ciertos autores, un número concreto de horas de formación y supervisión, o exigencias diversas respecto al análisis personal para que éste autorice suficientemente al aspirante -en ocasiones eterno aspirante- a psicoanalista.

Fue el propio Freud quien, preocupado por el futuro de la disciplina que había fundado, trató de mantener la pureza del psicoanálisis delegando su herencia en algunos de sus discípulos y en determinados criterios prácticos, que dominaron los primeros años de la IPA. Esto no impidió que, más adelante, muchos de sus seguidores se apartaran de sus preceptos, creando concepciones propias que han generado corrientes psicoanalíticas muy diversas y multitud de escuelas para su enseñanza. Es posible que estas disidencias internas, sumadas a la crítica que siempre acompañó al psicoanálisis en los círculos universitarios y científicos, provocaran que tras la muerte de Freud sus discípulos redoblaran esfuerzos en sistematizar la praxis psicoanalítica. Pero, paradójicamente, apoyándose en criterios que, si bien Freud enunció al modo de consejos, se han sostenido rígidamente, alejándose de la flexibilidad y adaptación a sus pacientes que se reflejan en toda su obra.

Sándor Ferenczi resulta un claro ejemplo de fidelidad inicial a Freud que, con el paso de los años, se transformó en un polémico distanciamiento, provocando en ambos una profunda 
decepción. Las palabras que encabezan este trabajo pertenecen a una de las cartas que intercambiaron, en la que el analista húngaro, ya aquejado de la enfermedad sanguínea que le produjo la muerte, le transmite al maestro la necesidad de alejarse de sus ideas. Y le señala, además, su autoritarismo, dado el gran temor que despertaba entre sus discípulos la posibilidad de disentir con él.

En su texto Confusión de lenguas entre los adultos y el niño ${ }^{1}$, Ferenczi (2009) explica el grave daño que se deriva del amor entre un adulto y un niño cuando se confunden sus lenguajes: el de la pasión, en el primer caso, y el de ternura, para el menor. De forma que deviene una situación incestuosa en la que el niño, paralizado por el temor, se identifica con el adulto quedando sometido automáticamente a su voluntad. Además, para defenderse de la agresión, el niño introyecta la vivencia, que desaparece como realidad exterior y, convertida en elemento intrapsíquico, puede tratarla como oniroide o alucinatoria, despojándole su carácter traumático para mantener la situación de ternura anterior. A costa, eso sí, de un estado de confusa división interna donde el infante ha perdido la confianza en el testimonio de sus sentidos. Ferenczi señala que este mecanismo ocurre frecuentemente entre analistas y maestros respecto a sus pacientes y alumnos. De modo que la transferencia fuerte a la que están fijados estos últimos se convierte en sumisión, lo que les impide comunicar sus discrepancias y diferenciarse de aquéllos, cayéndose en situaciones de verdadero abuso. Habríamos de pensar si es un mecanismo similar al que observamos en algunas instituciones psicoanalíticas, donde las intensas transferencias con determinados maestros, la rigidez en los formalismos prácticos y el rechazo a otras perspectivas dan lugar a coyunturas francamente alienantes.

No se trata, sin embargo, de aspirar a eliminar por completo las diferencias —visión por otra parte bastante ingenua- entre las diversas corrientes psicoanalíticas. Pero sí de aprovechar el enriquecimiento que suponen enfrentándolas con curiosidad y respeto. Así, dulcificando la mirada, con la actitud benevolente que empleamos con los niños o con los pacientes más carenciados —básicas para el establecimiento de un vínculo saludablepodremos dejar de lado debates obsoletos y encontrar en perspectivas aparentemente opuestas más semejanzas de las esperadas. Es el caso de la manida contraposición entre pulsión y objeto, que muchos autores ya se han encargado de cuestionar señalando la inevitable interdependencia entre ambos constructos ${ }^{2}$. Otros conceptos de la metapsicología freudiana, revisados a la luz de autores posteriores, adoptan puntos comunes desde visiones tan alejadas como la teoría intersubjetiva y la orientación lacaniana. Desde el enfoque relacional, por ejemplo, se aboga por estudiar la participación del analista en la escena terapéutica. Se concede menos importancia a la individualidad de paciente y terapeuta en favor de una dimensión tercera entre ambos. Y trata de eliminarse la asimetría 
que, en la teoría clásica, confiere al analista un saber del que, a través de sus interpretaciones, dependería el buen progreso de la cura. Es difícil no encontrar similitudes con algunas ideas de Lacan respecto a que la verdadera resistencia está del lado del analista3, reconociendo la interferencia de su deseo en el tratamiento; término éste, deseo del analista, que, como el de co-transferencia para los relacionales, se prefiere al de contratransferencia (Coderch, citado por Codosero, 2008; Rosales, s.f.). Asimismo, también desde esta orientación se ha superado la idea, ampliamente atribuida a Freud, de un inconsciente exclusivamente individual ${ }^{4}$. De forma que es en la mezcla o inmixión con el Otro, entendiendo a éste como discurso, que nace el sujeto lacaniano, en la hiancia, en el vacío bien podríamos situar aquí la terceridad relacional- producida como consecuencia de la imposibilidad para entendernos completamente, como seres que somos habitados por el lenguaje. Por último, ya hemos visto como esta carencia es, desde esta perspectiva, imposible de rellenar con el sentido. Por lo que, al igual que en la práctica intersubjetiva, se sugiere al analista abandonar la posición de saber y abstenerse de intervenciones que apunten a descifrar o construir nuevos significados a partir de las palabras del paciente.

Obviamente, debemos manejar estas semejanzas con prudencia, entendiendo que no corresponden a modelos comparables. Aun forzando ciertas similitudes, lo cierto es que reconocemos diferencias muy evidentes en la práctica analítica de cada orientación.

No obstante, a falta de claras evidencias sobre el mejor resultado de uno u otro enfoque, entiendo que no será desde el rechazo, sino desde el interés por conocer la práctica ajena, que podremos establecer una rica oposición dialéctica, en la que, defendiendo cada cual su esquema referencial, el psicoanálisis se vea fortalecido por la pluralidad y el diálogo entre sus practicantes. Me uno entonces a las palabras de Ferenczi en el mencionado artículo, Confusión de lenguas, en el que afirma:

Me agradaría que a partir de ahora concedieran más importancia a la manera de pensar y de hablar de sus niños, de sus pacientes y de sus alumnos, tras los cuales se ocultan críticas, de forma que pudieran aclarar la confusión de lenguas y aprovecharan la ocasión para aprender cosas (Ferenczi, 2009).

\section{REFERENCIAS}

Aguirre, A. (2015). Psicoanalistas independientes británicos. Contribuciones teóricas. (Trabajo de Fin de Grado, Universidad de Salamanca). Recuperado de https://gredos.usal.es/jspui/bitstream/10366/126616/1/TFG_AguirreRedinA_Psicoanalistasinde pendientes.pdf 
Aron, L. (2013). Un encuentro de mentes. Mutualidad en el psicoanálisis. Santiago de Chile: Universidad Alberto Hurtado.

Bellver, J.M. (17 de mayo de 2014). La gran escisión de Jacques Lacan. El mundo. Recuperado de http://www.elmundo.es/cultura/2014/05/17/5376944622601d637c8b4592.html

Bousseyroux, M. (2016). Lacan el borromeo. Ahondar en el nudo. Barcelona: S\&P.

Codosero, A. (2008). Pluralidad y diálogo en psicoanálisis [Coderch, J., 2006]. Aperturas psicoanalíticas, 30. Recuperado de http://www.aperturas.org/articulos.php?id=0000556\&a=Pluralidad-y-dialogo-en-psicoanalisis[Coderch-J-2006]

Delahanty (1992). Geopolítica de la psicología del yo. Contribuciones de David Rapaport al psicoanálisis. Imagen psicoanalítica, 1(1), 1-20. Recuperado de https://www.ampiep.org/publicaciones/wp-content/uploads/2016/o1/geopolitica-de-lapsicologia-del-yo.pdf

Ferenczi, S. (2 de octubre de1932). Correspondencia Freud Ferenczi de 1932 en contrapunto con el diario clínico. Recuperado de https://www.lacanterafreudiana.com.ar/CORRESPONDENCIA_FREUD_FERENCZI_DE_1932 EN_CONTRAPUNTO_CON_EL_DIARIO_CLINICO.pdf

Ferenczi, S. (2009). Confusión de lenguas entre los adultos y el niño. El lenguaje de la ternura y el lenguaje de la pasión. En Problemas y métodos del psicoanálisis (pp. 164-176). Bueno Aires: Paidós-Hormé (Trabajo original publicado en 1933).

Ferschtut, G. (2002). De los siete anillos a la cadena infinita. Psicoanálisis APdeBa, 25(1/2), 267293. Recuperado de http://www.apdeba.org/wp-content/uploads/Ferschtut5.pdf

García Badaracco, J. (2010). Sobre la "mente cerrada". Revista de Psicoanálisis, 67(12), 19-35.

Genovés, A. (2011). La clínica plurideterminista de Freud. El intercambio entre subjetividad, intersubjetividad y cultura. Recuperado de https://www.youtube.com/watch?v=JtIEImtG_4\&t $=5775$

Gómez, V. (25 de enero de 1980). A propósito de la disolución de la escuela freudiana de París. El país. Recuperado de https://elpais.com/diario/1980/01/25/cultura/317602807_850215.html

Green, A. (2014). Lo intrapsíquico y lo intersubjetivo. Pulsiones y/o relaciones de objeto. En El pensamiento clínico (pp. 37-73). Buenos Aires: Amorrortu.

Lacan, J. (2012). Acto de fundación. En Otros escritos (pp. 247-260). Buenos Aires: Paidós (Trabajo original publicado en 1964).

Lacan, J. (2013a). Variantes de la cura tipo. En Escritos 1 (pp. 311-346). Madrid: Biblioteca Nueva (Trabajo original publicado en 1955).

Lacan, J. (2013b). La dirección de la cura y los principios de su poder. En Escritos 2 (pp. 559-616). Madrid: Biblioteca Nueva (Trabajo original publicado en 1958).

Malecki, J., Matanó, G., y Zuzulich, S. (2013). El psicoanálisis en Francia: La escisión de 1969. Trabajo presentado en Cuarto Congreso Internacional de Investigación de la Facultad de Psicología de la Universidad Nacional de La Plata, Argentina. Recuperado de 
http://sedici.unlp.edu.ar/bitstream/handle/10915/45581/Documento_completo.pdf?sequence= $\underline{1}$

Martínez, J.M. (2017). ¿A qué se resisten los psicoanalistas?. Recuperado de https://www.youtube.com/watch?v=qyIrfrTMyoE

Meltzer, D. (1996). El proceso psicoanalítico. (4a ed.). Buenos Aires: Hormé (Trabajo original publicado en 1967).

Rosales, I. (s.f.). Deseo del analista, transferencia y contratransferencia. Recuperado de http://inesrosales.org/deseo-del-analista-transferencia-y-contratransferencia/

Saraspe, G.E. (2016). Aportes de Donald Meltzer al Psicoanálisis. Recuperado de https://www.kennedy.edu.ar/wp-content/uploads/bsk-pdf-manager/2016-o9-19_75.pdf

Sauval, M. (1998). El fracaso de las instituciones "psicoanalíticas". Recuperado de https://www.sauval.com/pdf/El\%2ofracaso\%2ode\%2olas\%2oinstituciones\%2opsicoanaliticas. pdf

Segal, H. (1985). Melanie Klein. Madrid: Alianza (Trabajo original publicado en 1979).

Velasco, R. (2009). ¿Qué es el Psicoanálisis Relacional?. Clínica e Investigación Relacional, 3(1), 5867. Recuperado de https://www.psicoterapiarelacional.es/Portals/o/eJournalCelR/V3N1_2009/7_Velasco_Que-esPsicoanalisis-Relacional_CelR_V3N1.pdf

Original recibido con fecha: 20/05/2018 Revisado: 25/5/2018 Aceptado: 30/05/2018 NOTAS:

\footnotetext{
${ }^{1}$ Freud se opuso, sin conseguirlo, a que Ferenczi presentará el texto en el XII Congreso de la IPA, celebrado en Wiesbaden en 1932.

2 "Si no hubiera falta de objeto, no sabríamos que la pulsión existe, puesto que es en ese momento cuando ella se manifiesta de manera apremiante. A la inversa, yo diría que no hay objeto, cualquiera que sea, que no esté animado e investido por las pulsiones y, más aún, habitado él mismo por sus propias pulsiones" (Green, 2014, p.45).

3 Martínez (2017), sin embargo, complejiza el entendimiento de esta conocida máxima lacaniana, dirigiéndonos a distintas partes de la obra de Lacan donde éste la aplicaría a una resistencia inconsciente del analista al propio psicoanálisis.

4 En realidad, Freud destacó el papel del inconsciente materno en la construcción del psiquismo y la dimensión interpersonal de la psicopatología, resultándole imposible disociar de la cura analítica la interacción humana, como ya estaba implícito en los conceptos de transferencia y contratransferencia (Genovés, 2011).
} 